\title{
ELECTROMAGNETIC DE-SHALING OF COAL
}

\author{
T.P.R. DE JONG*, M.B. MESINA and W. KUILMAN \\ Faculty of Applied Earth Sciences, Delft University of Technology, Mijnbouwstraat 120, \\ 2628 RX Delft, The Netherlands
}

(Received 22 December 2003; In final form 20 January 2004)

\begin{abstract}
The efficiency with which an electromagnetic sensor array is able to distinguish density and ash content of coal and shale mixtures was determined experimentally. The investigated sensor was originally designed for automatic metal detection and sorting in industrial glass recycle processing, where it is widely applied. In coal preparation, the results indicate good possibilities to remove automatically the remaining shale from the coal product, or to recover the remaining coal from the waste rock. Compared to alternative methods, the system has advantages of simple construction, insensitivity to fluctuating dust or moisture levels and a proven industrial reference. Applications can be either sorting of lump-sized coal or coal separation in the $10-50 \mathrm{~mm}$ size range in a dry preparation process.
\end{abstract}

Keywords: Coal; Pneumatic sorting; Electromagnetic sensor; Shale; Dry separation; Waste rock

\section{INTRODUCTION}

Run-of-mine (ROM) coal is usually diluted with considerable amounts of shale and other host rock. Over time higher dilution rates can be expected as a result of increased mining automation and depletion of thicker, high purity seams of undisturbed structure. Today, ROM coal having up to $50 \%$ ash content is no exception, of which, in many cases, the main part consists of free shale.

The majority of shale is effectively removed in a wet preparation plant (washery), usually by heavy media separation (HMS) or jigging. However, these methods cannot always be applied. In two specific cases it may be necessary to employ alternative methods:

1. Pre-washery lump sorting

2. When dry coal preparation is required due to:

(a) Arctic conditions.

(b) Arid conditions.

(c) Environmental constraints on process water use.

(d) Economic constraints.

(e) The case when only partial coal cleaning as pre-concentration is required.

Both cases will be discussed separately.

\footnotetext{
*Corresponding author. E-mail: T.P.R.deJong@ta.tudelft.nl
} 


\subsection{Pre-washery Lump Sorting}

Coal washery plants are usually designed for a maximum top feed size of 50 to $150 \mathrm{~mm}$. Oversize coal may be crushed, but especially when there is a strong host rock, coal percentage in the oversize can be as low as $20 \%$. Three options remain:

1. Crush the oversize and add to the washery feed.

2. Consider oversize as waste and accept the coal loss. At a $20 \%$ oversize coal content and a 2.5 to $10 \%$ oversize in the ROM, coal losses of 0.5 to $2 \%$ would occur.

3. Sort the oversize to recover pure coal and middlings (bony or banded coal), and discard pure rock as waste only.

The first option recovers practically all coal. Disadvantages are increased crusher maintenance costs, reduced washery capacity and increased media consumption per tonne of coal output. Besides, disturbing tramp material may be present that must be manually removed before crushing. In many cases the coal loss of the second option is economically unacceptable. It is obvious that whenever possible the third option is preferable. In principle it can be accomplished in three different ways: mechanical cleaning; hand sorting; and automatic sorting.

\subsubsection{Mechanical Cleaning}

For many operations a relatively small fraction of oversize ROM compared to other streams, as well as its high rock content, means that installation of a mechanical cleaning system, of considerable dimensions, because of the large top size, requires a large investment that in many cases cannot be justified. Exceptions are:

1. Washeries for coal from open cast mines that have ROM of a considerably larger size and hence justify mechanical treatment of oversize ROM. For instance, when the host rock is stronger than coal, rotary coal breakers are employed, effecting separation and crushing of oversize coal in one stage [1]. HMS can be applied for coarse oversize when, due to a weak host rock, coal breakers perform unsatisfactorily.

2. When further crushing is required in order to obtain sufficient liberation of coal (reduction of the middlings percentage).

\subsubsection{Hand Sorting}

Hand sorting is applied to recover coal from the oversize ROM. It requires only little investment, but manpower requirement is considerable [2-4]. Costs of hand sorting increase sharply with decreasing size as is shown in Table I.

Apart from size, the feed capacity is related to the percentage of material to be removed. Figure 1 shows data for $>100 \mathrm{~mm}$ coal. For $-100+50 \mathrm{~mm}$ coal the sorting capacity is around 0.75 to $1.0 \mathrm{t} / \mathrm{man}$ hour at a high percentage of impurity

TABLE I Capacity of hand sorting at average contamination levels [4]

\begin{tabular}{lc}
\hline Feed size $($ coal $)$ & $\begin{array}{c}\text { Tons removed } \\
\text { per man-shift }\end{array}$ \\
\hline$>150 \mathrm{~mm}$ & 12 \\
$150-75 \mathrm{~mm}$ & 7 \\
$75-32 \mathrm{~mm}$ & 2 \\
\hline
\end{tabular}




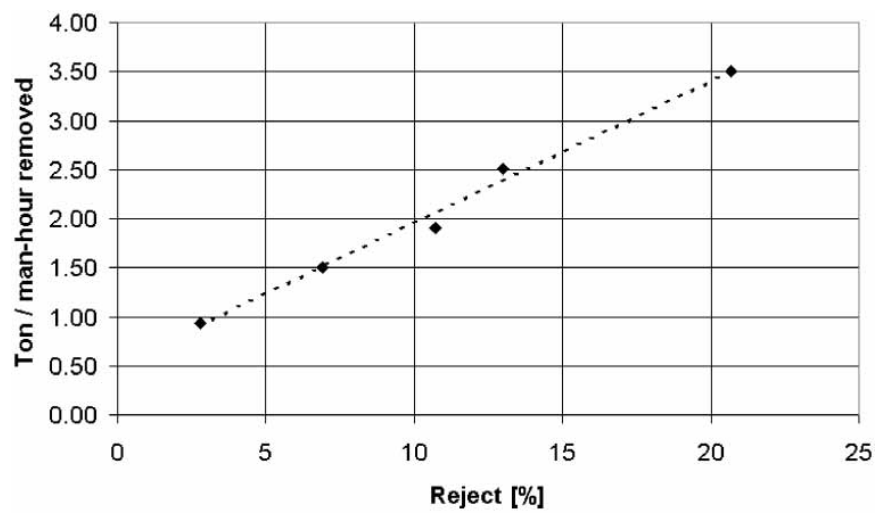

FIGURE 1 Hand sorting capacity as a function of reject percentage for $>100 \mathrm{~mm}$ coal [3].

TABLE II Distribution of coal, middlings and rock in mass $\%$ [3]

\begin{tabular}{|c|c|c|c|c|c|c|c|c|c|}
\hline \multirow[t]{2}{*}{ Size } & \multicolumn{3}{|c|}{ Feed } & \multicolumn{3}{|c|}{ Coal } & \multicolumn{3}{|c|}{ Reject } \\
\hline & Coal & Middl. & Rock & Coal & Middl. & Rock & Coal & Middl. & Rock \\
\hline$>150 \mathrm{~mm}$ & n.a. & n.a. & n.a. & n.a. & n.a. & n.a. & 57.7 & 26.8 & 15.5 \\
\hline $75-150 \mathrm{~mm}$ & 89.8 & 7.7 & 2.5 & 95.8 & 3.1 & 1.1 & 67.5 & 18.8 & 13.1 \\
\hline $63-75 \mathrm{~mm}$ & 92.9 & 3.7 & 3.4 & 94.1 & 3.8 & 2.1 & 65.5 & 15.6 & 18.9 \\
\hline
\end{tabular}

and favourable conditions for sorting. At the average impurity level twice as many sorters are needed for $-100+50 \mathrm{~mm}$ coal as compared to $>100 \mathrm{~mm}$ coal in order to get equivalent ash reduction.

In order to maintain constant quality, in theory, sufficient sorters would need to be available for the maximum levels of impurity that can occur. However, in practice the speed of the conveyor is adjusted to the level of impurities for an optimized utilization of manpower. Proper sorting practice demands even tonnage of coal to be uniformly sized and spread out in a mono-layer (a layer not exceeding the height of the individual particles). The conveying speed typically amounts between 0.15 and $0.3 \mathrm{~m} / \mathrm{s}$, and should not exceed $0.4 \mathrm{~m} / \mathrm{s}$.

For hand sorting, the distinction is hampered by the coal being wet, which is frequently the case due to dust spraying. In this case the fine coal clings to the lumpsized material irrespective of its composition, giving all lumps a similar appearance.

Hand sorting results were evaluated by determining the float and sink fraction in a $1.6 \mathrm{~g} / \mathrm{cm}^{3}$ liquid [3]. Tests indicated that for the 25 to $50 \mathrm{~mm}$ sizes of a $4.5 \%$ ash feed a slight reduction in ash of only $0.15 \%$ per man could be obtained (reducing it to approximately $4.1 \%$ in total), while approximately $0.3 \mathrm{t}$ was removed per man hour. The rejects still contained $40 \%$ of $<1.6 \mathrm{~g} / \mathrm{cm}^{3}$ floats. For the $-100+50 \mathrm{~mm}$ fractions the average result was slightly better, but still leaving $2 \%>1.6 \mathrm{~g} / \mathrm{cm}^{3}$ material in the coal, while for $-50+25 \mathrm{~mm}$ this amounted on average $4.5 \%$. The obtainable qualities of the coal, middlings (bony or banded coal) and rock are illustrated by experimental data in Table II.

Hand sorting is coming under increased pressure due to high labour costs, especially in the developed world. Under such circumstances, the sorters can only recover limited 
amounts of coal or limit the recovery to tramp material only. This is hand inspection rather than hand sorting. In addition considerable health and safety risks associated with lifting heavy material for long period of time and dust exposure must be taken into account.

\subsubsection{Automatic Sorting}

Since the early 20th century the factors discussed above regarding mechanical cleaning and hand sorting led to considerable development work in automating the sorting process. Related previous work on electric, X-ray and optical detection of coal and shale should be mentioned [5-9]. Despite the availability of techniques that seem suitable for coal sorting and numerous patents, experience showed that the introduction of automatic sorting has encountered various problems and as a result it is currently viewed with a certain level of scepticism [10]. The reasons are:

1. Actual results did not meet expectations that were often (unrealistically) high.

2. The systems were not able to handle variations in size, shape and composition that are encountered in practice.

3. Maintenance requirements and unexpected breakdowns were unacceptably high.

4. Poor organization and the absence of a proper service network suitable for serving the mining industry.

5. High investment costs.

6. High energy use.

7. Low capacity, especially for smaller sizes.

Due to (at least some of) the listed reasons automatic sorting of coal lumps has never really taken off, despite its considerable potential. However, various authors recently addressed the remaining hurdles in automatic lump sorting [11-13].

\subsection{Dry Coal Preparation}

As mentioned, a totally 'dry' flow sheet for the preparation of coal can be particularly advantageous. The specific merits and problems of dry coal preparation compared to conventional wet preparation have been discussed in earlier work [2,3,14-17]. One of the main problems of conventional dry processes, which rely on pneumatic mechanical cleaning, is the lower separation efficiency and inability to concentrate the fines. This made many existing dry operations obsolete, due to higher dilution rates and smaller particle size ranges that are associated with the ongoing progress in mining automation (increased use of drum-type longwall shearers) and increased use of water sprays against dust. Major difficulties in dry cleaning of fines are related to a typical moisture content between 5 and $15 \%$, making the material sticky. It is these moisture levels that are particularly sensitive for unfavourable particle agglomeration.

A recent study carried out by Delft University of Technology (The Netherlands), Nottingham University (UK) and RWTH Aachen (Germany), supported by the European Coal and Steel Community, had an objective to evaluate dry preparation and investigate potential improvements [18]. Based on sampling at a dry preparation plant in Germany, pilot scale separation experiments and flow sheet simulations, it was concluded that when the feed is properly sized and suitable dry density separators are employed, such as air tables, air jigs or dry sand fluidized bed separators, and when 
the product is additionally after-cleaned with an automatic sorter, qualities and recoveries that are competitive to conventional wet separation can be obtained.

\subsection{Electromagnetic De-shaling of Coal}

Some minerals and rocks show variable electrical conductivity and magnetic interaction [19]. This means that such minerals could be detected or separated using devices that are able to measure their electric and magnetic properties. In general, most minerals are weakly conductive and have electrical conductivity much lower than that of iron, even which is a poor conductor compared to copper.

For small fractions of $-5+2 \mathrm{~mm}$, high gradient magnetic separation (HGMS) showed significant results in coal separation based on magnetic properties of the minerals [20,21]. It was shown that the difference in magnetic properties between coal and shale can be used for separation, and hence for distinction and automatic sorting. Often the differences may be too small for mechanical separation, but still adequate for detection and electronic amplification.

The difference in electrical conductivity between shale and coal is easily verified on hand pieces with a sensitive conductivity meter. In 1937 Birtley developed an experimental machine for automatic sorting of shale from coal, based on electrical conductivity [5]. Each lump passes separately beneath a set of brushes and based on the electrical conductivity of a lump a gate rises to deflect the lump to the shale chute.

Later two similar methods applied for sorting of minerals based on their electrical properties were described: (1) low voltage; and (2) high voltage sorting [22]. The main difference between the two methods consists in the voltage applied between a metal belt carrying the minerals and an electrode, which touches the minerals. The recorded potential difference is used to differentiate conductive minerals. The low voltage method is mainly applied to wet pieces, while the high voltage method is exclusively applied to dry lumps.

More recent techniques produced acceptable results in using metal detectors for preconcentration of pyritic sulphide and copper-cobalt ores [23]. The developed systems seemed to respond only to those minerals that are metal based. So far no information has been found regarding use of this device for coal concentration or shale removal.

It can be concluded that when certain conditions are met, improved automatic sorting has a perspective in the above-mentioned applications in coal cleaning. Recent developments in automatic sorting technology, as currently applied in the recycling industry and especially in glass recycle processing, resulted in lower processing costs and increased availability and quality of the automatic sorting systems based on optical, electromagnetic and X-ray systems [24,25]. Today, in these applications, more than two decades of industrial high-capacity sorting experience is available. Currently these systems are widely applied for glass recycle cleaning and metal scrap sorting (Fig. 2).

The suitability of the existing sensors and sorting devices for coal preparation still needs to be addressed. Both electrical and magnetic properties may vary considerably depending on the mineralogical composition of coal and shale. The experimentally determined sharpness of separation is indicative of the effectiveness of the method for similar coal types. Therefore the objective of the present work is to provide quantitative performance of a state-of-the-art electromagnetic sensor applied to coal. When based on this approach, further development is successfully pursued, automatic 


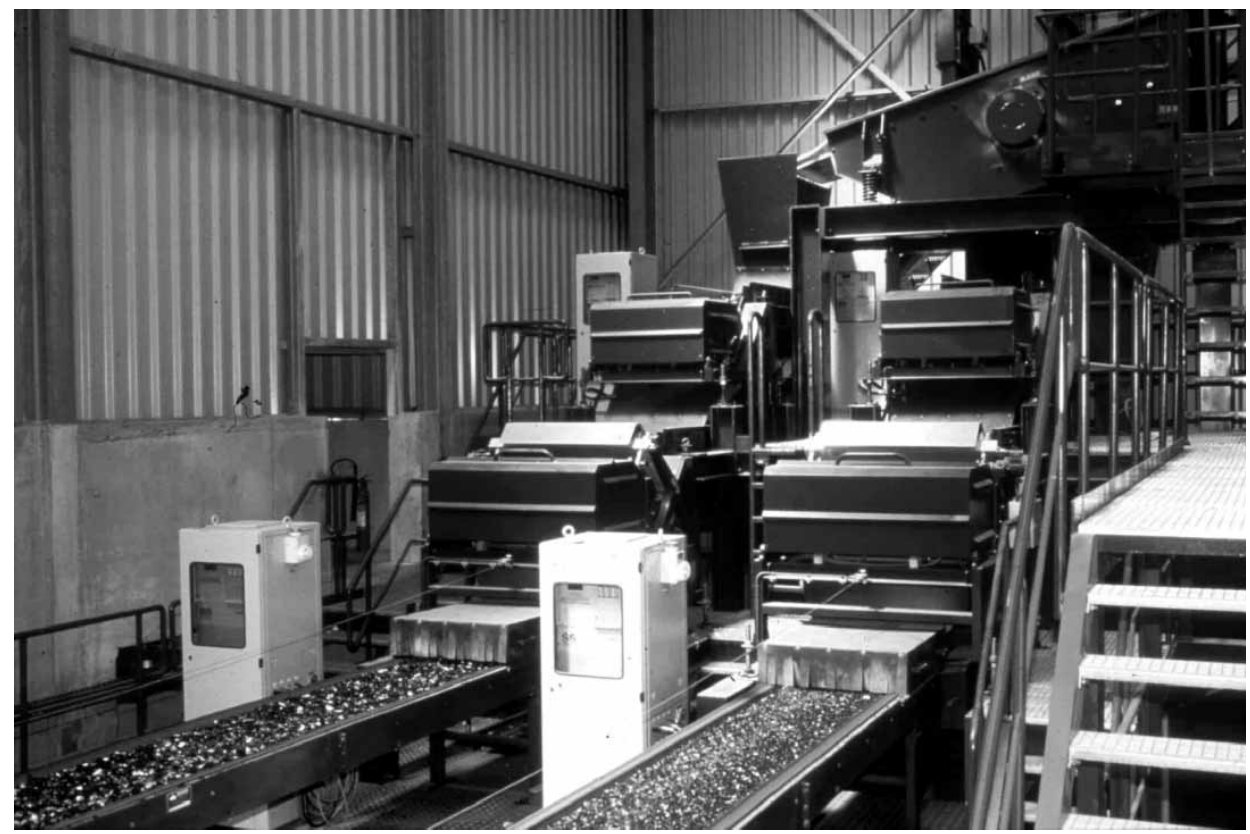

FIGURE 2 A two-line, two-stage automatic sorting system for glass recycle. Each line has a capacity of 10 to $20 \mathrm{t} / \mathrm{h}$. A single plant may contain 20 to 40 sorting units at plant capacities up to $400 \mathrm{kt} / \mathrm{y}$.

sorting may form a key element for bridging the quality gap that currently exists between dry and wet preparation of coal.

\subsection{System Requirements}

A potentially successful automatic coal sorting system should fulfil the following requirements:

- Capacity approx. 10 to 1000 particles per second and per unit (10 for the larger lumps, 1000 for medium sized coal). This is approximately equivalent to approx. $90 \mathrm{t} / \mathrm{h}$ for shale or $45 \mathrm{t} / \mathrm{h}$ for coal of $150 \mathrm{~mm}$ and $42 \mathrm{t} / \mathrm{h}$ for shale and $21 \mathrm{t} / \mathrm{h}$ for coal of $25 \mathrm{~mm}$. As in glass processing, it may prove more economical to install parallel similar units for higher capacities instead of specifically designing larger units.

- Low effect on separation sharpness when feed fluctuations occur (fluctuating particle size, composition and moisture content).

- Processing costs, including maintenance and depreciation less than $€ / \mathrm{t}$.

- Favourable maintenance record for $>5000 \mathrm{~h} / \mathrm{y}$ operation under prevalent industrial conditions (temperature, humidity, dust fluctuations, vibrations from nearby equipment, insensitive for tramp material, etc.).

- Low headroom requirements enabling integration into existing plants.

- Safe: not causing explosion hazard; no unacceptable emissions of dust and noise; and no accessible moving parts.

Further, it was assumed that it was more useful to base the initial system on components with a proven industrial record, rather than trying to obtain the theoretically 
highest possible separation sharpness with a complex desktop system. Components should be simple, strong and reliable, and should be able to meet the mentioned requirements as much as possible, in order to indicate whether industrial automatic coal sorting is a viable option. The optimization of the system for application in coal can be addressed in successive studies.

\section{EXPERIMENTAL PROCEDURE}

Since coal and shale show differences in magnetic as well as in electrical properties, it was decided to investigate a sensor type that generates a variable signal depending on both properties. Besides, the signal of electromagnetic sensors is insensitive to moisture, dust, and other surface contaminations. Another condition was that the sensor has a proven industrial record in automatic sorting for comparable applications.

\subsection{Equipment}

Based on these considerations, an $\mathrm{S}+\mathrm{S}$ electromagnetic sensor was selected for further investigation [26]. It is equipped with electronic circuits capable of selective response to differences in electrical and magnetic properties of shale and coal. The same sensor is widely applied to automatic glass sorting for the removal of metallic contaminations down to $1 \mathrm{~mm}$ in size. For glass sorting the system has a capacity of about 10 to $20 \mathrm{t} / \mathrm{h}$ per meter sensor width. Sensor widths of a unit are usually between 0.75 and $1.5 \mathrm{~m}$. The sorting mechanism is normally based on the control of an array of air jets with resolution between 4 and $16 \mathrm{~mm}$, depending on particle shape. For coal, having a lower density but more voluminous shape, compared to crushed packing glass, the unit capacity would be approximately similar. For shale, the capacity would be approximately twice as high, and for mixtures in between, depending on their ratio.

The system used for coal inspection consists of a ramp, a sensor mounted below the ramp, a processing unit and a computer for data interpretation and visualization, as is shown in Fig. 3. The system is capable of controlling pneumatic actuators, but in the
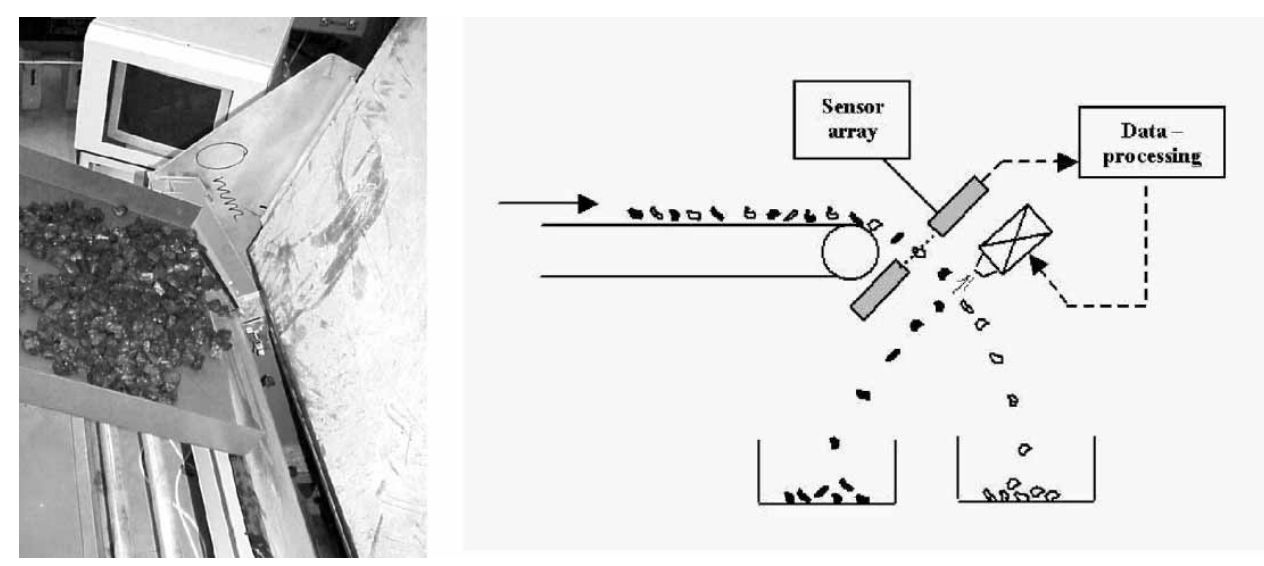

FIGURE 3 A machine used for electronic shale detection. The material slides down a ramp across a horizontal sensor array below it. The shale as well as coal particles can be ejected, depending whether the feed consists mainly of coal or waste rock. 
present set-up they were not installed. The feed slides across the sensor at velocities between 2 and $3 \mathrm{~m} / \mathrm{s}$. The system memorises the signals measured when the particles slide down and transmits this information to a processing unit that is able to interpret the signal. Before the final experiments, data acquisition and parameter settings of the sensor were optimized in order to obtain the best coal-shale distinction.

Each scanned particle generates a voltage signal (U), which is sent to the processing unit, where it is digitized and transmitted to a computer via a serial communication bus. The voltage varies from 0 to $3000 \mathrm{mV}$ depending on the electrical and magnetic properties of the particles. For every single particle the sensor records a voltage U. The minimum corresponds to a situation when no particle is present and a signal is recorded when particles pass the sensor.

\subsection{Sample}

The coal and shale that was initially investigated was a mixture of different types from several German and UK coal mines within the size range 20 to $50 \mathrm{~mm}$. The particles were split into density classes, counted and numbered (Fig. 4). The density classes were $1.2-1.3,1.3-1.4,1.4-1.5,1.5-1.6,1.6-1.7,1.7-1.8,1.8-2.0,2.0-2.4$ and $2.4-2.8$ $\mathrm{g} / \mathrm{cm}^{3}$. After the initial experiments, the results of which are shown in Figs 5 and 6, the ash content of each particle was determined by total oxidation at elevated temperature.

For the partition curve determination, the results of which are shown in Figs. 7 and 8, a single coal type, sampled in September 2002 from the dry coal preparation plant of Dr A. Schäfer Bergbau GmbH (Saarwellingen, Germany), the 20 to $30 \mathrm{~mm}$ fraction was taken and split in the laboratory into the same density classes, until each class contained a minimum of 35 particles.

For the determination of the effect of moisture, the results of which are shown in Fig. 9, another sample was taken from the same plant. The sample was visually split into coal and shale.

\subsection{Procedure}

In the initial experiments, the coal sample of Fig. 4 was scanned piece by piece, and the relationship between density classes and the measured voltage amplitude $U$ of the individual particles was established. Afterwards ash content was determined.

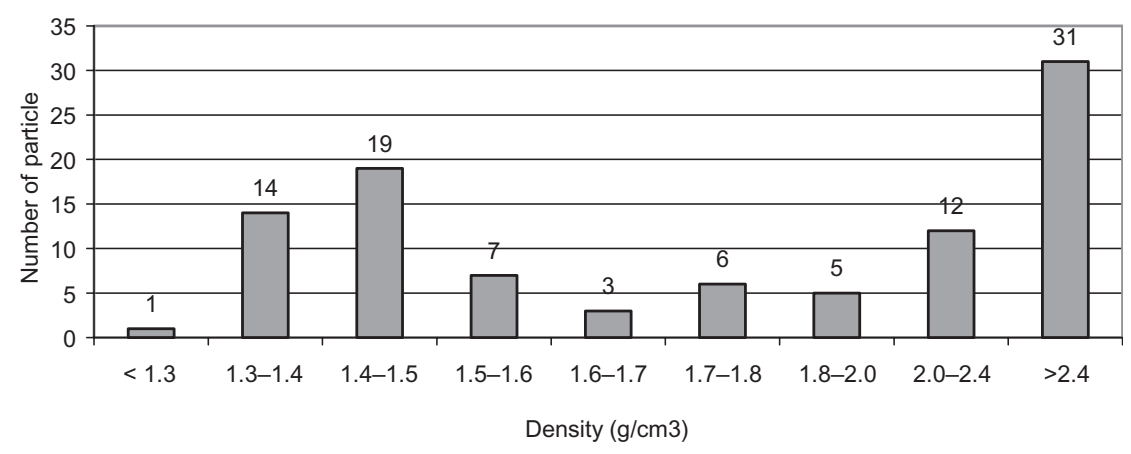

FIGURE 4 Density distribution by particle number of the investigated mixture of coal and shale as used for the initial experiments, the results of which are summarized in Figs. 5 and 6. 


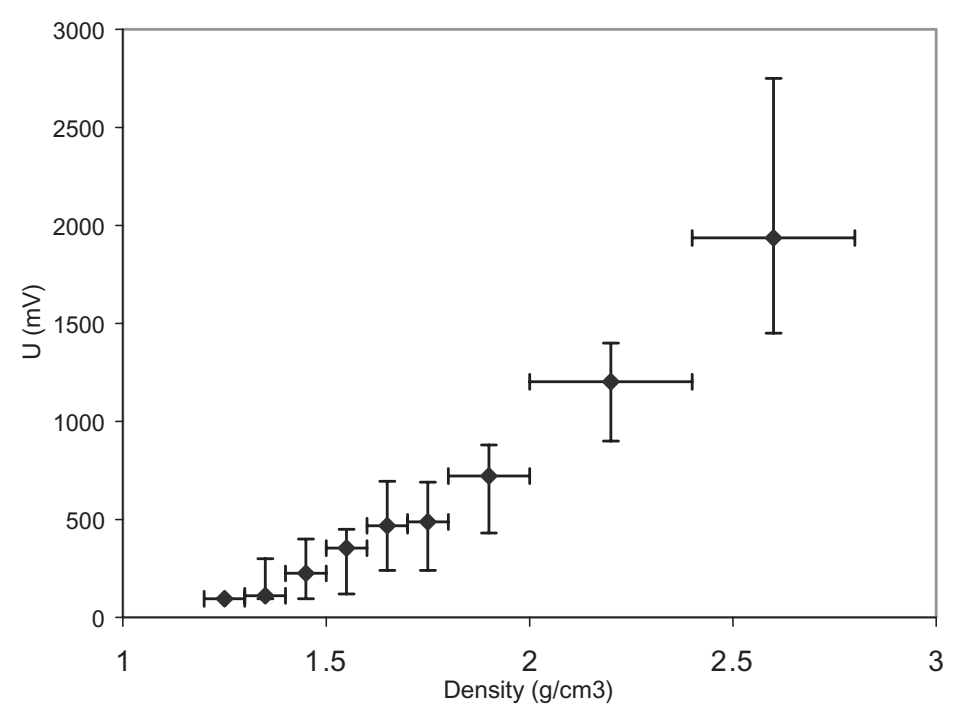

FIGURE 5 Voltage U versus density of different coal samples.

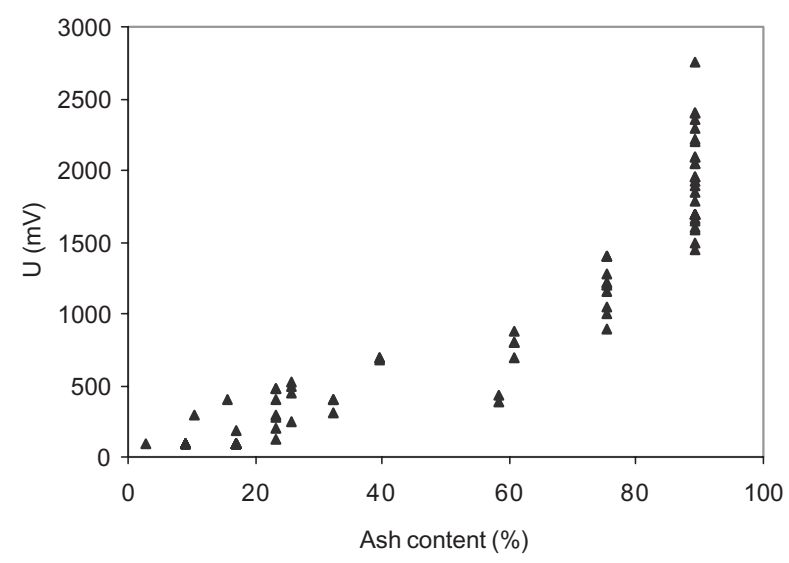

FIGURE 6 Voltage U versus the ash content classes.

In the second series of experiments, density partition curves were determined from the Saarwellingen coal sample for a range of voltage cut-off values that correspond to a cut-off density range between 1.4 and $2.7 \mathrm{~g} / \mathrm{cm}^{3}$. As has already been mentioned, each density class contained 35 particles. The curves indicate the maximum coal quality that can be obtained when $100 \%$ ejection accuracy is assumed. In practice, the ejection efficiency is equipment and feed rate dependent. It has not been investigated in the present work, but can be determined observing existing automatic sorters for comparable material.

In the final series, before scanning, a coal sample of the same source was visually split into five groups of coal and shale, of an equal number of particles and rinsed in tap water and water with increasing salinity of $10,20,40$ and $300 \mathrm{~g} / \mathrm{L}$ of dissolved $\mathrm{NaCl}$. 

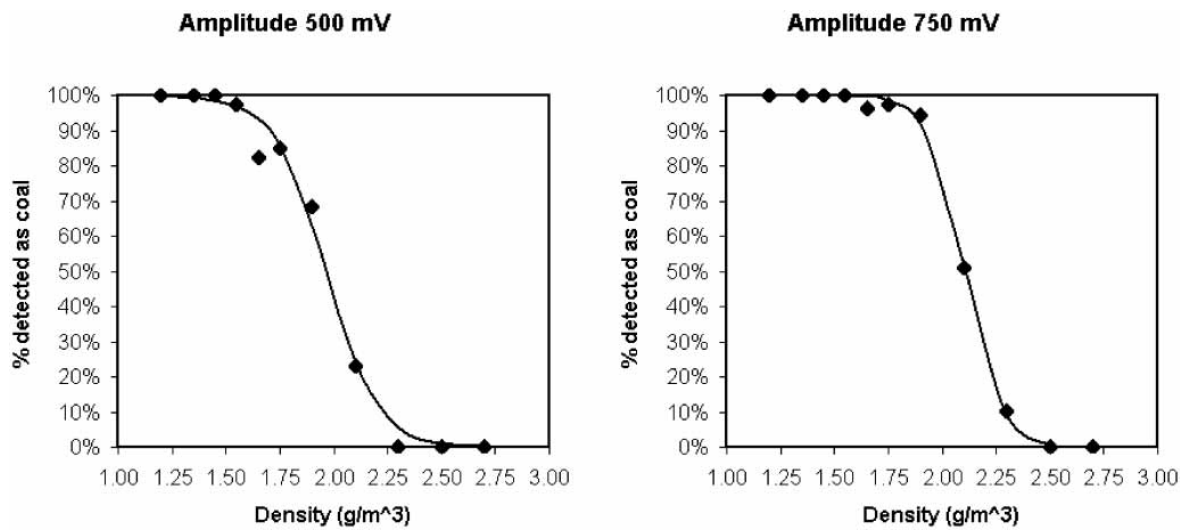

FIGURE 7 The partition density curves for cut-point density $1.96 \mathrm{~g} / \mathrm{cm}^{3}$, with $E_{p}=0.12$ (left) and $2.11 \mathrm{~g} / \mathrm{cm}^{3}$ with $E_{p}=0.08$ (right).

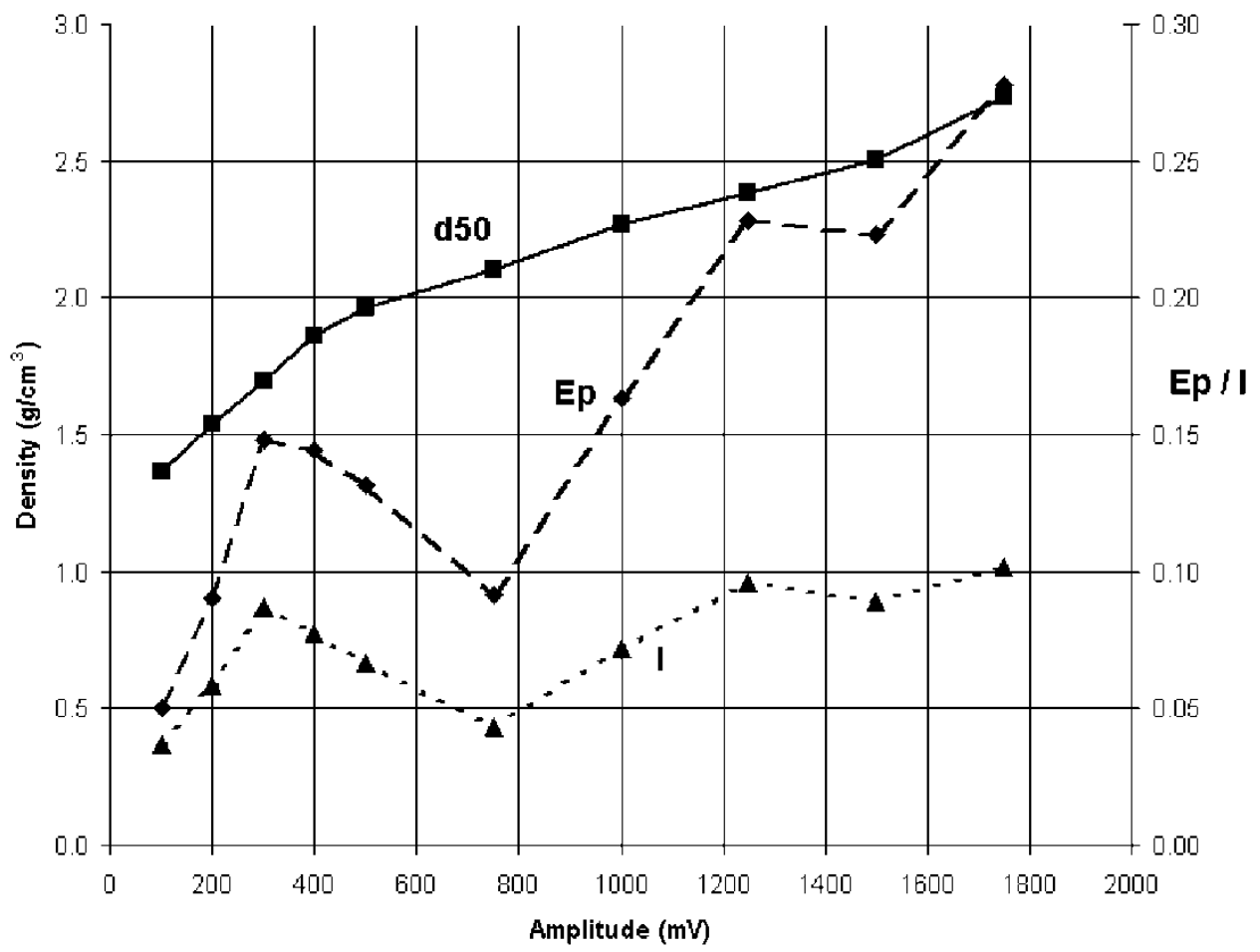

FIGURE 8 The cut-point density $\left(d_{50}\right)$, Écart probable moyen $\left(E_{p}\right)$ and imperfection $(I)$ as function of amplitude.

\section{RESULTS}

Each particle of the mixed coal sample (Fig. 4) was scanned individually, weighed and it was determined to which density class it belonged. The width of the horizontal bars in Fig. 5 represents these density classes, while the width of the vertical bars represents 


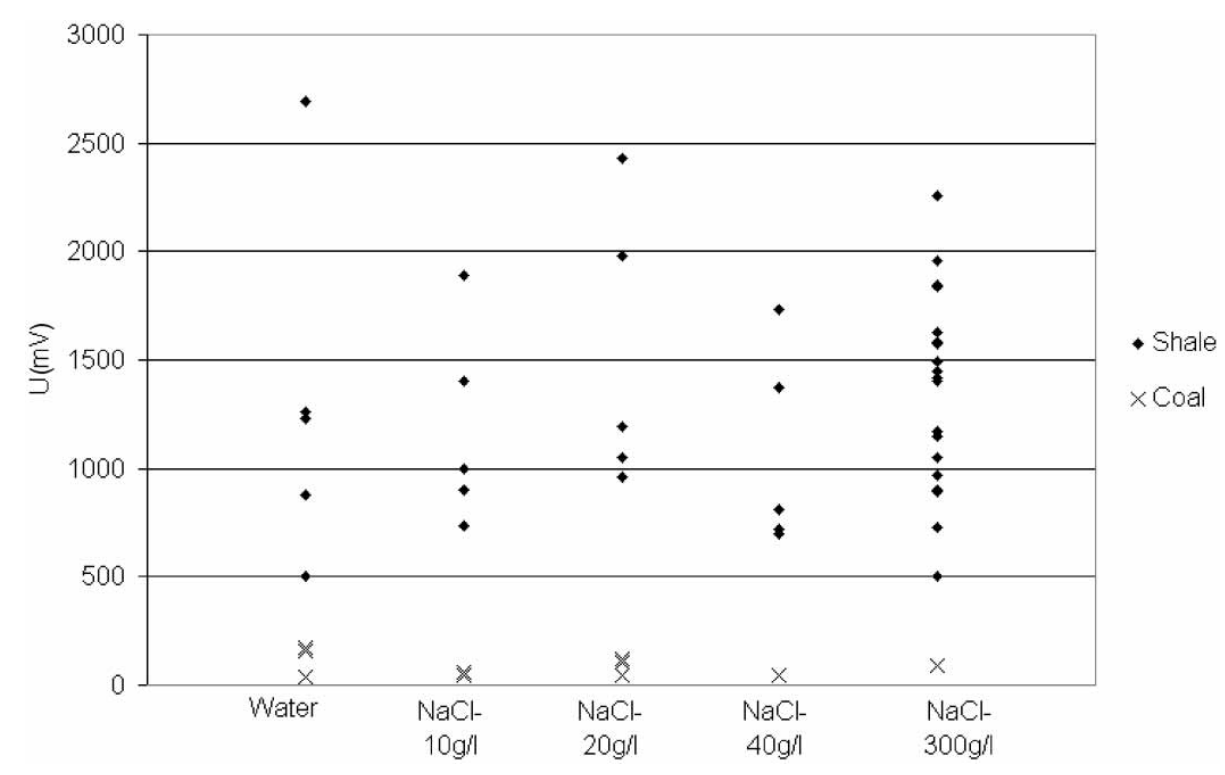

FIGURE 9 The coal/shale distinction for different particles, visually sorted into shale and coal, after rinsing in water of variable salinity.

the total range of the observed voltages of all particles comprising that class. Particles having low density show smaller variations in voltage $U$ compared to particles with higher density mainly due to the increased width of the density classes.

Most coal is valued mainly on the basis of ash content. After the experiments, the particles were visually split into coal and shale and the ash content of the considered particles was analyzed for each density class, resulting in the data shown in Fig. 6.

Mass and recorded voltage amplitude were determined for all particles from the second sample (the Saarwellingen coal density classes). By defining a specific threshold for the amplitude, a density partition curve can be constructed. If the measured amplitude is below the threshold, the particle is recognized as 'coal' and above it as 'shale'. This was done for amplitudes of 100, 200, 300, 400, 500, 750, 1000, 1250, 1500 and $1750 \mathrm{mV}$. Figure 7 shows the experimental partition data points at 500 and $750 \mathrm{mV}$ (diamonds). The relatively small sample resulted in certain data scatter. Therefore the data points were fitted with the least squares with a function of format:

$$
Y=\frac{1}{1+e^{\left(d-d_{50}\right) / d_{50}^{\prime}}}
$$

resulting in the continuous curves shown in Fig. 7.

In this equation, $d_{50}$ is the density cut-point (value at $50 \%$ ), and $d_{50}^{\prime}$ the gradient at this point, equal to $\tan \left(\alpha_{d 50}\right)$ with $\alpha_{d 50}$ being the angle of the curve at $d=d_{50}$. The factor $d_{50}^{\prime}$ is known as the separation sharpness.

From all fitted curves the 'Écart probable moyen' or $E_{p}$ was determined to enable direct comparison with $E_{p}$ values of other separation equipment as usually given in 
coal preparation literature:

$$
E_{p}=\frac{d_{75}-d_{25}}{2}
$$

where $d_{25}$ and $d_{75}$ are densities at the 25 and $75 \%$ recovery.

A certain disadvantage is that $E_{p}$ depends on the cut-point density $\left(d_{50}\right)$, hence operations at various values of $d_{50}$ cannot be directly compared. In these cases the 'Imperfection' $I$ can be used:

$$
I=\frac{E_{p}}{d_{50}}=\frac{d_{75}-d_{25}}{2 d_{50}}
$$

the values of $d_{50}, E_{p}$ and $I$ are given in Fig. 8 as a function of amplitude voltage, with density on the left-hand vertical scale, and $E_{p}$ and $I$ on the right-hand scale.

The final sample was scanned after rinsing in water with variable salinity. No effect of salinity on the coal-shale distinction was observed, as is shown in Fig. 9. It was also observed that the coal-shale distinction was the same for dry material and material with adhered moisture.

\section{CONCLUSION AND DISCUSSION}

\subsection{Conclusions from the Experimental Work}

- The investigated electromagnetic sensor transmits from each particle in the size range 20 to $50 \mathrm{~mm}$, scanned at a velocity between 2 and $3 \mathrm{~m} / \mathrm{s}$, an electronic signal from which the density and/or ash content can be determined.

- The sensor distinguishes coal and shale within the cut-point densities of $1.5 \mathrm{~g} / \mathrm{cm}^{3}$ to $2.3 \mathrm{~g} / \mathrm{cm}^{3}$ with sharpness expressed as $E_{p}$, ranging from $\approx 0.10$ to $\approx 0.15$.

- The effective cut-point density can be electronically adjusted within the entire density (or ash content) range occurring in a typical coal and shale mixture.

- Moisture and moisture salinity do not affect distinction between coal and shale.

\subsection{General Conclusions}

- An automatic sorting system equipped with an electromagnetic sensor may provide a cost-effective and relatively low investment cost alternative to hand sorting or other more expensive types of sensors (for instance, optical and X-ray).

- The system has a considerable potential to out-perform hand sorting in terms of capacity and quality at a lower cost.

- The investigated system is already widely applied to industrial automatic sorting in comparable industrial environments, which would enable rapid introduction of this principle in coal preparation or in other areas (e.g. ore sorting). Maintenance and operational costs are readily estimated by means of comparison with applications where the systems are already in use. 


\subsection{Discussion}

- The relatively small size of the sample used in the tests resulted in certain data scatter: more extensive trials should be carried out on specific coal types before the results are sufficiently accurate and generic for a deep techno-economical analysis. The present results merely indicate the potential of the system.

- The system used has not been specifically designed for this application. The authors believe that significant improvements in detection can be achieved by optimizing sensor design and data processing. In addition to optimizing the resolution of the amplitude of the voltage signal regarding coal-shale detection and optimizing it for a typical size, the shape and density ranges as encountered in practice, the phase shift can be simultaneously measured [27]. This provides an electromagnetic contour image of the scanned particles with the same sensor, so without the need to use an additional camera with related lighting and dust problems. Basic particle shape and size data can be electronically derived from it and combined with the amplitude data for a better distinction. The benefits of this multi-feature approach have been demonstrated in earlier work [28,29].

- The actuator performance must be established separately. The separation performance of the system is determined by a combination of the separation sharpness of detection and actuator performance. From experience it is known that actuator performance approximates $100 \%$ for lump-sized sorting at low particle feed rates (all particles detected are indeed removed and none are removed that are not detected). This applies to typical coal lump sorting applications. It is also known that for medium sized fractions (dry separation down to $20 \mathrm{~mm}$ ) the actuator efficiency may drop sharply when the system is overfed. Large numbers of adjacent particles are also ejected by the air blasts, or the recovery time of the valves is insufficient for the high feed rate of particles that must be removed. This situation must be avoided by proper circuit design and process control. In general, the lower the percentage of material to be removed and the larger the material, the higher the actuator efficiency. Therefore the fraction that is the lowest in percentage (remaining coal in shale or remaining shale in coal) is always removed.

- As in flotation or comminution, system circuits operating with several units under different settings may show a much better overall performance compared to a single unit only.

- Applications can be either lump-sized coal sorting or coal separation in the 10 to $50 \mathrm{~mm}$ size range in a dry preparation process.

- Pilot scale experiments on industrial scale are required for further evaluation.

\section{References}

[1] T. England (Ed.), Coal Preparation in South-Africa, The South African Coal Processing Society, Johannesburg, 2002.

[2] J.B. Morrow. The preparation of coal, Trans. Canadian Inst. Min. and Met. (1931).

[3] D.R. Mitchell et al. (Eds.), Coal Preparation, 2nd Edn., The American Inst. of Mining and Metall. Engrs, Inc., New York, 1950.

[4] SACPS. Coal Preparation Course, Vol. I, Section 6, South African Coal Processing Society, Johannesburg, 1977.

[5] Colliery Engineering, The Birtley Electric Coal Picker, January 1937.

[6] G.W. Bloomfield, D.L. Slight and P.G. Smith, The electronic coal separator, Proc. 5th Int. Coal Prep. Congr., Government Printing Office, Washington DC, 1966, 323-330. 
[7] D. Butel, W.J. Howarth, J. Rogis and K.G. Smith, Coal sorting, Coal Prep., 12 (1993), 203.

[8] D.E. Jenkinson, P.B. Gough, H.G. King and K.W. Daykin, Coal sorting by X-ray transmission, Proc. 10th Int. Min. Proc. Congr., The Institution of Mining and Metallurgy, London, 1974.

[9] A.Z. Yourovsky, V.D. Goroshko, V.I. Korshunov and I.D. Remesnikov, New dry processes for coal preparation - magnetic, aero-suspension, radiometric, Proc. 4th Int. Coal Prep. Congr., Harrogate,Yorkshire, 1962.

[10] J.D. Salter and N.P.G. Wyatt, Sorting in the minerals industry: past present and future, Min. Engin., 4 (1991), 779.

[11] Dry Beneficiation of Coal by Laser Sorting, project C6050, Australian Coal Research Limited, 1997.

[12] Z. Xiulong and L. Hongjun, A brief introduction to automatic separator of coal refuse, CCERC, No.5, Hepingli, Beijing, 2000.

[13] C.M. Bartle, A method for the non-invasive assessment of properties of materials including coal and wool, Int. Patent Appl., WO 01/09596, 2001.

[14] N.C. Lockhart, Dry beneficiation of coal, Powder Technol., 40 (1984), 17.

[15] J. Donelli, Potential revival of dry cleaning of coal, The Australian Coal Rev., October (1999).

[16] J.A. van Houwelingen and T.P.R. de Jong, Dry cleaning of coal: review, fundamentals and opportunities, Proc. 5th European Coal Conf., Mons, Belgium, 2002.

[17] T.P.R. de Jong, J.A. van Houwelingen and W. Kuilman, Automatic sorting and control in solid fuel processing: opportunities in European perspective, Proc. 5th European Coal Conf., Mons, Belgium, 2002.

[18] T.P.R. de Jong, J.A. van Houwelingen, W. Kuilman, M.B. Mesina and M.A. Reuter, ECSC-project 7220-PR-066 TU Delft report: An evaluation of the economic benefits of pneumatic dry cleaning processes, Report Delft University of Technology, Delft, (nr. TA.GT.2003.12) 2003.

[19] W.M. Telford, L.P. Geldart, R.E. Sheriff and D.A. Keys, Applied Geophysics, Cambridge University Press, Cambridge, 1976.

[20] G.S. Dobby and D.R. Kelland, Magnetite coal separation by continuous HGMS, IEEE Trans. Magn., 18 (1998), 1698.

[21] M.R. Parker, High gradient magnetic separation, Physics in Technology, 12 (1981), 268.

[22] N.L. Weiss, SME Mineral Processing Handbook, Vol. 1, Society of Mining Engineers, Kingsport Press, Kingsport, TN, 1985.

[23] R. Sivamohan and E. Forssberg, Electronic sorting and other preconcentration methods, Min. Engn., 4 (1991), 797.

[24] T.P.R. de Jong, W.L. Dalmijn and H.U.R. Kattentidt, Dual energy X-ray transmission imaging for concentration and control of solids, Proc. 22nd Int. Min. Proc. Cong. IMPC-2003, Cape Town, 2003.

[25] W.L. Dalmijn, T.P.R. de Jong, F. Fraunholcz and H.J. Glass, A method and apparatus for analysing and sorting a flow of material, Int. Patent Appl., WO 02/50521, 2002.

[26] S+S Metallsuchgeräte und Recyclingtechnik GmbH, Regener Straße 130, D-94513 Schönberg, Germany (2003).

[27] M.B. Mesina, T.P.R. de Jong and W.L. Dalmijn, Improvements in separation of non-ferrous scrap metals using an electromagnetic sensor, Phys. Sep. Science Engn., 12 (2003), 87.

[28] H.U.R. Kattentidt, T.P.R. de Jong and W.L. Dalmijn, Multi sensor identification and sorting of bulk solids, Control Engineering Practice, 11 (2003), 41.

[29] T.P.R. de Jong, H.U.R. Kattentidt and W.L. Dalmijn, Cameras watch over glass cullet quality, Recycl. Int., October (2003), 48. 